Research Paper

\title{
Sohlh2 suppresses epithelial to mesenchymal transition in breast cancer via downregulation of IL-8
}

\author{
Shufang $\mathrm{Ji}^{1, *}$, Wenfang Zhang ${ }^{1, *}$, Xiaoli Zhang ${ }^{1}$, Chunyan Hao ${ }^{2}$, Aijun Hao ${ }^{1}$, Qing \\ Gao $^{1}$, Hongying Zhang ${ }^{3}$, Jinhao Sun ${ }^{4}$, Jing $\mathrm{Hao}^{1}$ \\ ${ }^{1}$ Key Laboratory of The Ministry of Education for Experimental Teratology, Department of Histology and Embryology, School \\ of Medicine, Shandong University, Jinan 250012, PR China \\ ${ }^{2}$ Department of Pathology, School of Medicine, Shandong University, Jinan 250012, PR China \\ ${ }^{3}$ Department of Biology, Jinan Vocational College of Nursing, Jinan 250000, PR China \\ ${ }^{4}$ Department of Human Anatomy, School of Medicine, Shandong University, Jinan 250012, PR China \\ *These authors contributed equally to this work
}

Correspondence to: Jing Hao, email: haojing@sdu.edu.cn

Keywords: Soh/h2, IL-8, EMT, metastasis, breast cancer

Abbreviations: EMT, epithelial-to-mesenchymal transition; Sohlh2, spermatogenesis- and oogenesis- specific basic helix-loop-helix transcription factor2; IL-8, interleukin 8; FBS, fetal bovine serum; ChIP, chromatin immunoprecipitation

Received: September 25, $2015 \quad$ Accepted: June 16, $2016 \quad$ Published: June 30, 2016

\section{ABSTRACT}

Breast cancer is one of the deadliest cancers worldwide due to its strong metastasis to other organs. Metastasis of breast cancer involves a complex set of events, including epithelial-mesenchymal transition (EMT) that increases invasiveness of the tumor cells. We previously identified sohlh2 is a tumor suppressor in the pathogenesis of ovarian cancer. However, the functions of sohlh2 in breast cancer cell migration and invasion remain unknown. Here we report a novel sohlh2/IL-8 signaling pathway in the invasive breast cancer. We observed sohlh2 expression was downregulated in the metastatic breast cancer. Ectopic sohlh2 expression in breast cancer cells reduced EMT and inhibited cell migration and invasion in vitro, and metastasis in vivo. Moreover, the depletion of sohlh2 induced the opposite effects to ectopic sohlh2 expression. RNASeq data from a sohlh2 knockdown breast cancer cell line showed that after sohlh2 depletion, the mRNA level of interleukin 8 (IL-8) was significantly increased in these cancer cells, which consequently increased secretion of IL-8 protein. Using chromatin immunoprecipitation and reporter assays, we demonstrated that sohlh 2 bound to IL-8 promoter and repressed its activities. The enhanced migration and invasion in sohlh2 -ablated MCF-7 cells were blocked by knockdown of IL-8 expression, while exogenous IL-8 neutralized the anti-migratory and invasive activities of sohlh2 in MDA-MB-231cells. Overall, these results demonstrate that sohlh2 functions as a tumor metastasis suppressor via suppressing IL-8 expression in breast cancer.

\section{INTRODUCTION}

Breast cancer is one of the leading causes for cancer death in females worldwide [1]. The majority of breast cancer-related deaths are caused by metastatic progression, which is a complex process involving a succession of cell biological events [2, 3]. Currently, treatment options for metastatic breast cancers are limited and ineffective. Therefore, tremendous efforts have been made to understand the mechanisms how metastasis occurs, which will help to develop more rational approaches for treatments of metastatic breast cancers. However, how metastases are formed remains less understood. Mounting evidence shows that in epithelial cancers, including breast cancers, induction of epithelial-mesenchymal transition (EMT) is a major event that provides the mobility to cancer cells to generate metastases [4].

EMT is characterized by the loss of epithelial characteristics and acquisition of a mesenchymal phenotype, which confers the ability for cancer cells to 
invade adjacent tissue and disseminate to distant sites [5]. The process of EMT is featured with the loss of epithelial markers, such as E-cadherin and occludin, and acquisition of mesenchymal markers, such as N-cadherin and vimentin. Many factors can stimulate the EMT process. A group of transcription factors have been demonstrated to be capable of orchestrating EMT in cancer progression, including Snail, Slug, and ZEB2/SIP1 [6, 7]. Hence clarification of EMT mechanisms can greatly benefit our understanding to tumor metastases.

A spermatogenesis and oogenesis specific basic helix-loop-helix (bHLH) transcription factor, sohlh2, is one of important transcription factors in large bHLH family $[8,9]$. bHLH proteins play critical roles in many physiological processes including cellular differentiation, cell cycle arrest and apoptosis [10]. The conserved bHLH domain is involved in homo- or hetero-dimerization to form a functional transcriptional unit that binds to the canonical E-Box response element (CANNTG) in the promoter of many genes [10]. In human, our previous data showed that high level of sohlh2 expression was observed in various normal tissues, especially epithelial tissue. We also demonstrated that overexpression of sohlh2 resulted in the inhibition of ovarian cancer cell proliferation, migration and invasion [11, 12]. Moreover, targeted expression of sohlh2 inhibited ovarian cancer growth and metastasis in vivo $[11,12]$. These findings suggest that sohlh2 acts as a novel tumor suppressor.

Interleukin 8 (IL-8), alternatively known as CXCL8, is a pleiotropic chemokine involved in variety of pathophysiological processes. It has been shown to play an important role in human cancers by modulating metastasis and angiogenesis [13]. IL-8 activates two cell-surface, G protein-coupled receptors (CXCR1 and CXCR2) in multiple intracellular signaling pathways [14]. Increased expression of IL- 8 and/or its receptors has been observed in a number of cancers including breast cancer $[15,16]$. Increased level of serum IL- 8 has been reported in metastatic breast cancers, which correlates with early dissemination and survival [17]. Moreover, it has been demonstrated that IL-8 is involved in the regulation of EMT process $[18,19]$.

In this study, we demonstrated that sohlh2 overexpression inhibited EMT and metastasis in breast cancer cells. Conversely, sohlh2 silencing induced EMT in transformed and malignant human mammary epithelial cells, resulting in enhancement of migration and invasion in vitro. These functional effects of sohlh2 were achieved by directly binding to IL- 8 promoter and controlling IL-8 transcriptional expression. Our findings provide novel mechanistic insights of sohlh2 in breast cancer metastasis and a reasonable explanation for our clinical observation that low sohlh2 expression is correlated with breast cancer metastasis, suggesting that sohlh2 may serve as a potential therapeutic target for advanced breast cancers.

\section{RESULTS}

\section{Sohlh2 reduction in breast cancer correlates with metastasis}

Sohlh2 expression was examined in 77 cases of primary human invasive ductal breast cancer specimens, 16 cases intraductal carcinoma in situ, and 25 cases adjacent tissues of breast cancer by immunohistochemitry (IHC) assay. Sohlh2 expression was observed in all $(100 \%)$ adjacent tissues, all (100\%) intraductal carcinoma in situ, and in 47 of $77(61.04 \%)$ of invasive ductal carcinoma. Sohlh2 immunostaining was both nuclear and cytoplasmic (Figure 1A). Sohlh2 expression was significantly lower in invasive ductal carcinoma with $(n=29)$ and without metastasis $(n=48)$ compared to intraductal carcinoma in situ $(n=16)$ and adjacent tissues $(n=25)$, with a median IHC-score 8.04 for adjacent tissues, 6.76 for intraductal carcinoma in situ, 4.96 for breast cancer without matastasis, and 3.6 for breast cancer with matastasis, respectively $(p<0.01$; Figure 1B). Moreover, sohlh2 expression was negatively associated with lymph node metastasis and distant metastasis in breast cancer $(p<0.01$, Figure 1B).

We sought to examine the mRNA and protein levels of sohlh2 expression in human breast cancer cell lines (MDA-MB-231, MCF-7) and transformed mammary epithelial cell lines (HBL-100, MCF-10a) by qPCR and Western blot analysis. As shown in Figure 1C and 1D, sohlh2 mRNA and protein were lowly expressed in human breast cancer cell lines, especially in MDA-MB-231 cells, compared with those in HBL-100 and MCF-10a cells. These data strongly suggest that sohlh2 expression is significantly suppressed in human breast cancer cells.

\section{Sohlh2 represses migratory and invasive capacities of breast cancer cells in vitro}

The effect of sohlh2 on cell migration was assessed by wound healing assay. Sohlh2 overexpression in MDAMB-231 cells significantly slowed down closure of the wound area compared with control cells (Figure 2A). This result was further verified by Transwell assay (Figure 2B). Sohlh2 overexpression in MDA-MB-231 cells showed a less degree of invasion through Matrigel (Figure 2B). Conversely, sohlh2 silencing dramatically enhanced the migratory and invasive capacities of HBL100, MCF-10a and MCF7 cells (Figure 2C-2E). These results indicate that sohlh2 represses migratory and invasive behaviors in breast cancer cells.

\section{Sohlh2 inhibits metastasis in vivo}

To extend our in vitro observations, we investigated whether sohlh2 can decrease metastatic capacity of breast cancer cells in vivo. The functional relevance of sohlh2 
for metastasis in vivo was assayed. Sohlh2 overexpression in MDA-MB-231 cells dramatically decreased, while sohlh2 knockdown in MCF-7 cells significantly increased the number of metastatic tumors in the lungs and livers via tail vein injection (Figure 3A-3C). The spontaneous tumor dissemination was also evaluated in the lungs by injection MDA-MB-231 cells in the mammary fat pad. As shown in Figure 3D, sohlh2 overexpression dramatically decreased the number of metastatic tumors in the lungs. These results indicate that sohlh2 negatively regulates the metastasis of breast cancer cells. Therefore, the in vivo results further validate the critical role of sohlh 2 in breast cancer metastasis.

\section{Sohlh2 reduces EMT}

EMT plays a critical role in promoting metastasis of breast cancer. To investigate whether sohlh2 is involved in EMT in breast cancer cells, the expression of EMT biomarker proteins was examined. We showed that sohlh2 overexpression in MDA-MB-231 cells significantly

A

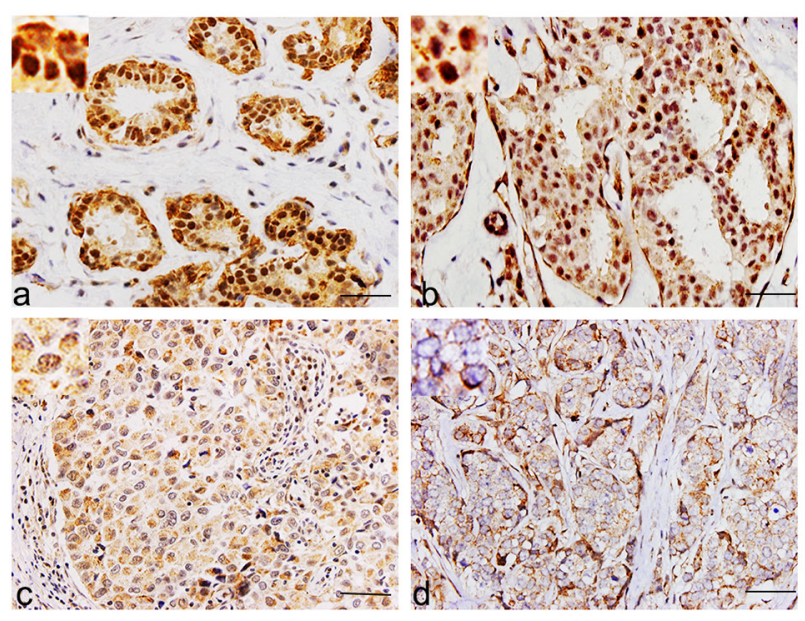

C

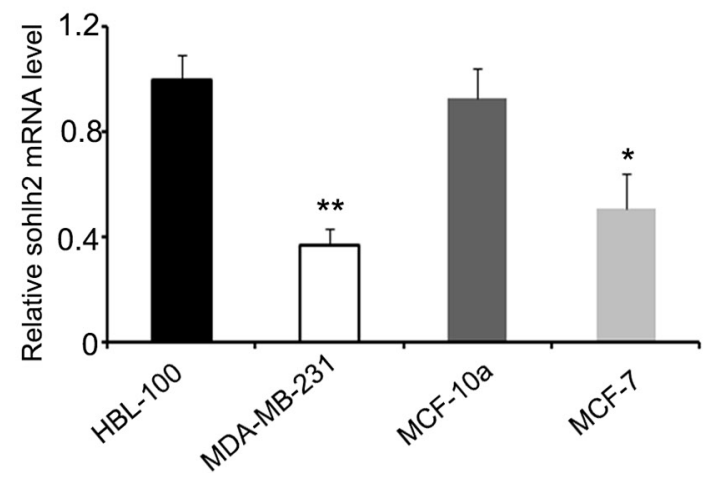

increased the expression of epithelial marker E-cadherin but decreased the levels of mesenchymal markers ( $\mathrm{N}$-cadherin, fibronectin, and vimentin) (Figure 4A-4D). Moreover, the expression of EMT biomarker mRNAs correlated with their corresponding protein levels (Figure 4C), suggesting that sohlh2 regulates the expression of EMT biomarkers at the transcript level. Conversely, Sohlh2 silencing in MCF7 cells exhibited fibroblastic properties (Figure 4A). Sohlh2 silencing significantly decreased the level of E-cadherin but increased the level of $\mathrm{N}$-cadherin, fibronectin, and vimentin (Figure 4B-4D). Thus, these findings support that sohlh2 plays an important role in the regulation of EMT/ MET plasticity in breast cancer cells.

\section{Sohlh2 downregulates IL-8 expression}

To better understand the mechanisms how sohlh2 is involved in breast cancer progression, we performed gene expression profiling sohlh2-ablated and control MCF7 cells. RNA-sequence analysis identified a list of differentially expressed genes after sohlh2

B

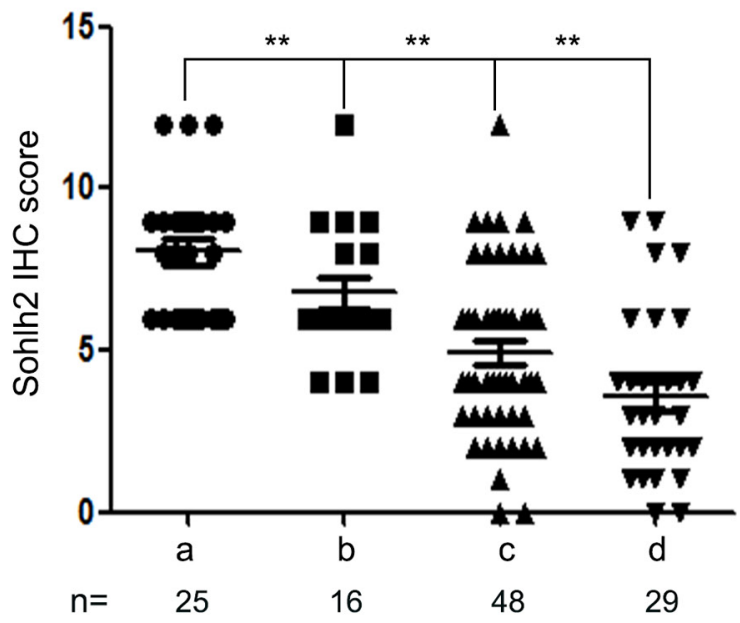

D

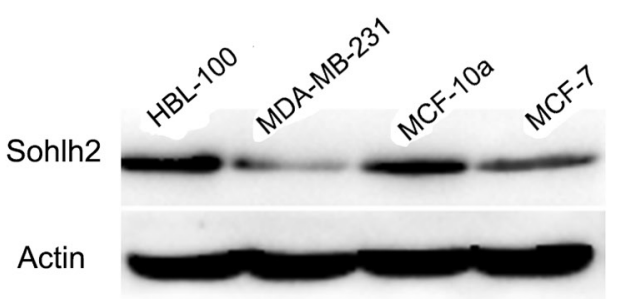

Figure 1: Reduced expression of sohlh2 is correlated with the metastasis of breast cancer. (A) Immunohistochemical staining of Sohlh2 in adjacent tissues of breast cancer (a), intraductal carcinoma in situ (b), breast cancer without or with metastasis (c, d). A representative image from each group is shown. Scale bar $=50 \mu \mathrm{m}$. (B) Intensity of sohlh2 staining was scored from 0 to 12 . Graph representing the average intensity of sohlh2 staining for adjacent tissues of breast cancer (a) versus intraductal carcinoma in situ (b), breast cancer without or with metastasis (c, d). (C, D) The mRNA and protein expression of sohlh2 were analyzed by qPCR (C) and Western blot (D) in the transformed mammary epithelial cell lines (HBL-100, MCF-10a) and breast cancer cell lines (MDA-MB-231, MCF-7). $\beta$-actin was used as a loading control. $* P<0.05 ; * * P<0.01$. 
A
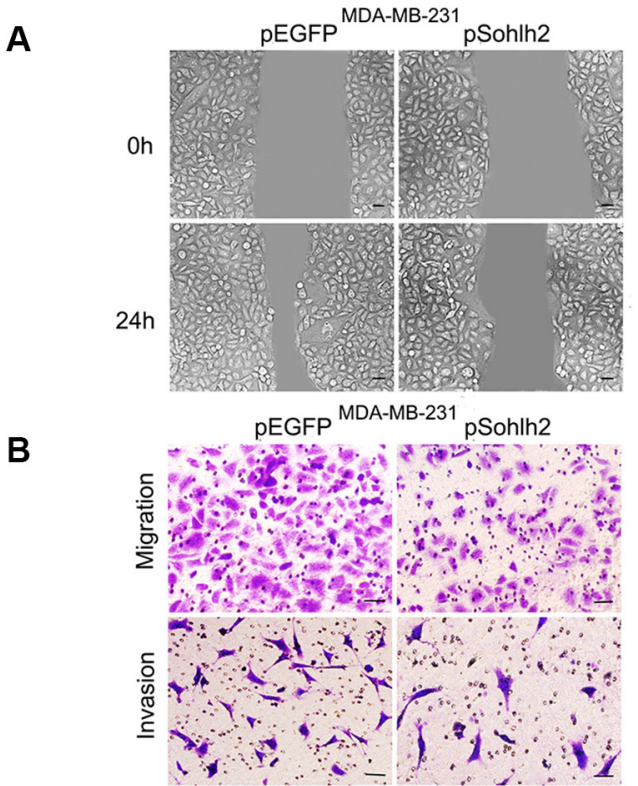

C
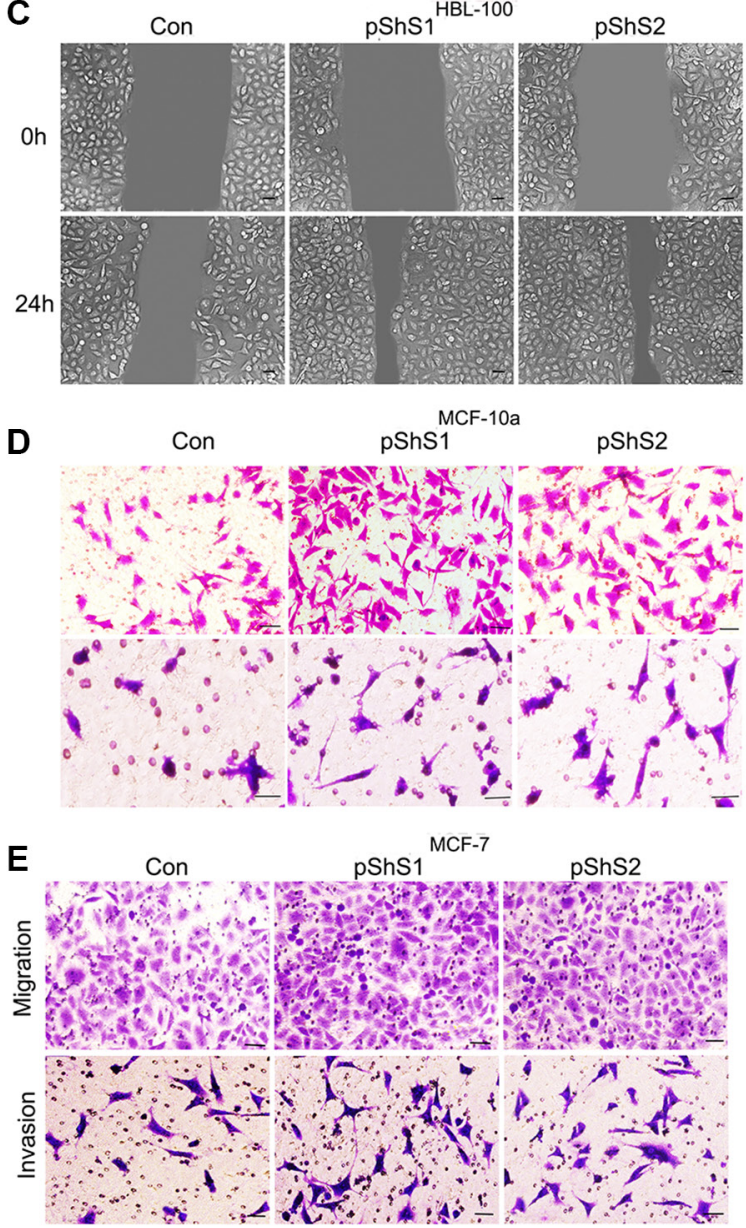
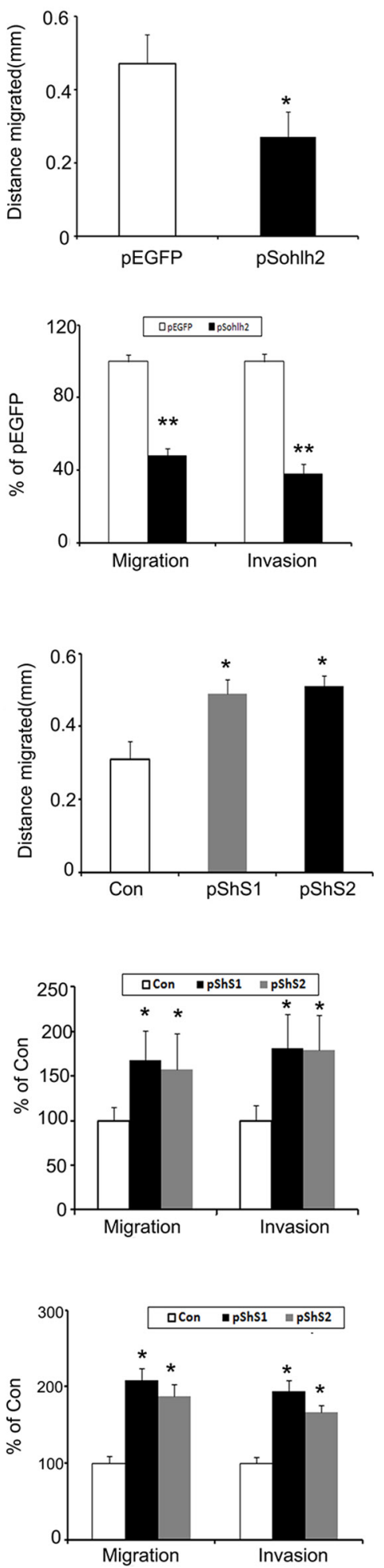

Figure 2: Sohlh2 expression reduces breast cancer cell migration and invasion. (A) Sohlh2 overexpression decreases cell migration in MDA-MB-231 cells. (B) Sohlh2 overexpression inhibits cell migration and invasion in MDA-MA-231 cells. (C) Sohlh2 knockdown increases cell migration in HBL100 cells. (D) Sohlh2 knockdown increases cell migration and invasion in MCF-10a cells. (E) Sohlh2 knockdown increases cell migration and invasion in MCF-7 cells. The representative images were shown on the left and the quantitative analysis was shown on the right. The cell migration distance (in A and C) was quantified by wound healing assay, while quantification of migrated cells through the membrane and invaded cells through Matrigel of each cell line (in B, D, E) was carried out by transwell assays. Scale bars indicate $100 \mu \mathrm{m}(\mathrm{A}$ and C) or $50 \mu \mathrm{m}$ (B and D). All results are obtained from three independent experiments. ${ }^{*} P<0.05 ;{ }^{* *} P<0.01$. 
deletion, including upregulation of IL-8 (Figure 5A; Supplementary Table S1). It has been shown that IL-8 is involved in the regulation of EMT $[18,19]$. These evidence prompts us to hypothesize that sohlh2 exerts these functions possibly via downregulation of IL-8. To test this, we first determined whether IL- 8 is a downstream target of sohlh2 in breast cancer cells. Expression of IL- 8 in the cells with altered expression was further

A Lung
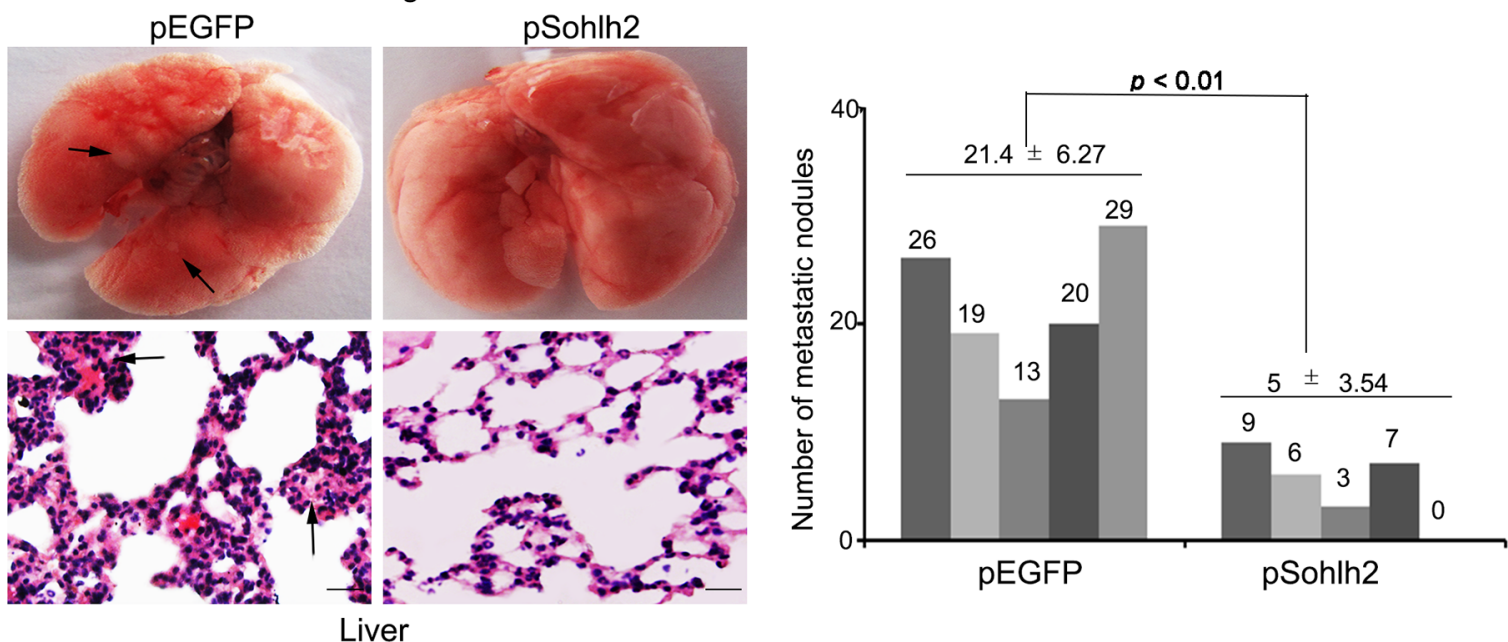

B

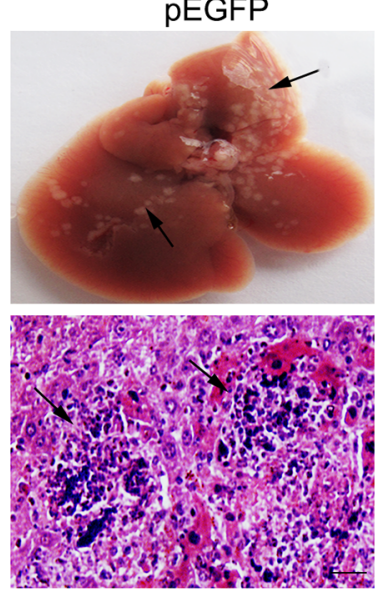

pSohlh2
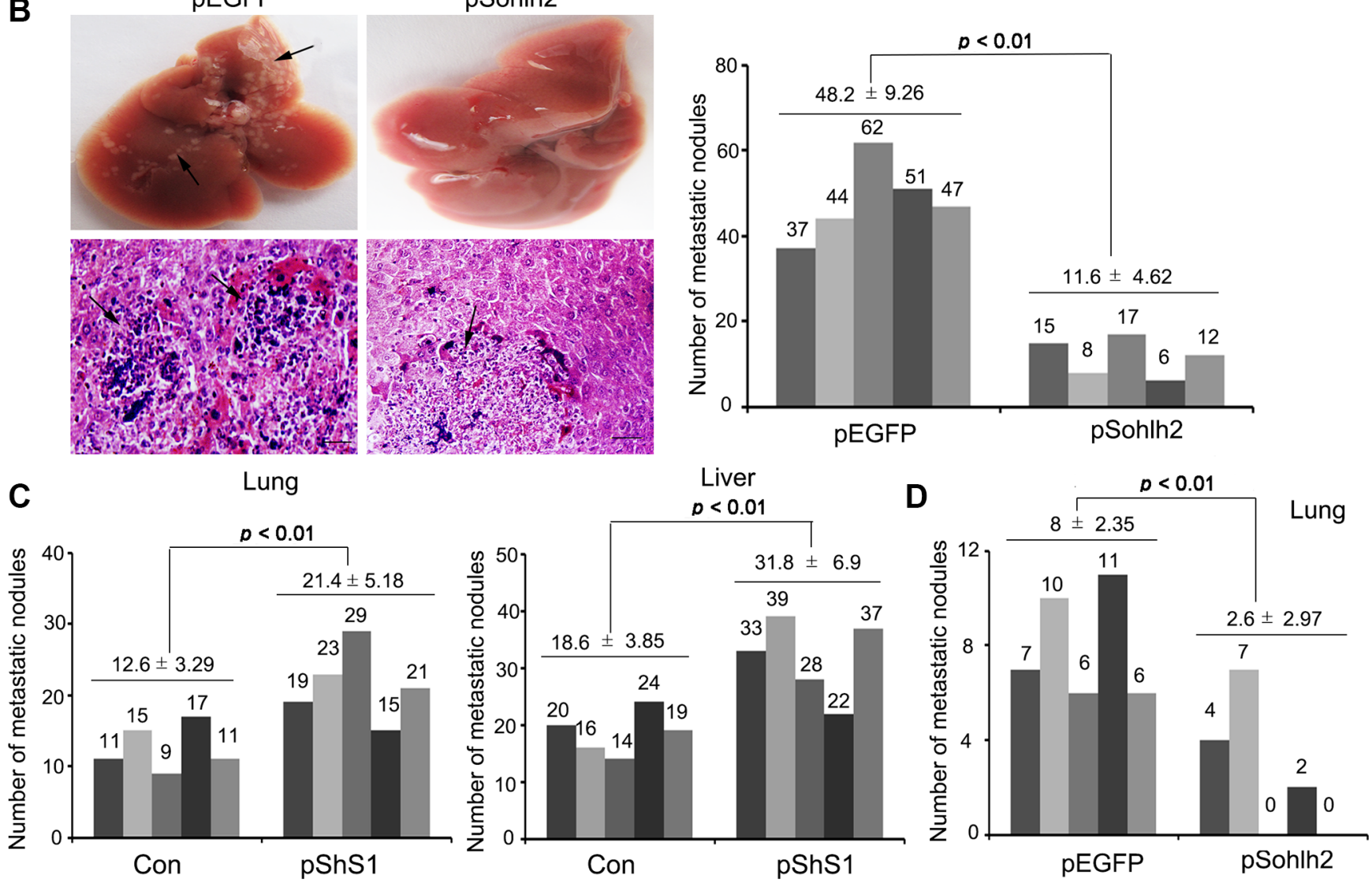

Figure 3: Sohlh2 inhibits breast cancer metastasis in mice. Sohlh2-expressing (sohlh2-silencing) or parental cells were injected into BALB/c nude mice via tail vein. The mice were sacrificed after 8 weeks, and tumor colonies in the lung and liver were examined. (A) Representative images of lung samples and sections with H\&E staining (right), metastasis nodules formed by parental and sohlh2expressing MDA-MB-231 cells were quantified (left). (B) Representative images of liver samples and sections with H\&E staining at 8 wk after injection were shown (right), metastasis nodules formed by parental and sohlh2-expressing MDA-MB-231 tumors were quantified (left). (C) Metastasis nodules in lungs and livers formed by parental and sohlh2-silencing MCF-7 cells were quantified. (D) Sohlh2expressing or parental cells were injected in mammary pad of BALB/c nude mice. Spontaneous metastasis nodules in lungs formed by parental and sohlh2-expressing MDA-MB-231cells were quantified. Arrows show metastasis nodules. Scale bars indicate $50 \mu \mathrm{m}$. 
evaluated by qPCR, Western blot and ELISA. Sohlh2 overexpression in MDA-MB-231 cells significantly decreased IL-8 mRNA and protein expression, whereas sohlh2 silencing in MCF7 cells significantly increased IL-8 mRNA and protein expression (Figure 5B-5D). These data suggest IL- 8 expression is regulated by sohlh2 at transcriptional level.

\section{Direct inactivation of IL-8 gene by sohlh2}

Sohlh2 functions as a bHLH transcription factor to regulate gene expression directly. To elucidate how sohlh2 inhibits IL-8 expression, the sequences in IL-8 promoter region were analyzed. Ten putative sohlh2-binding sites, E-boxes with a motif sequence CANNTG, were identified in the proximal ( -2000 to +100 base pairs) promoter region of IL-8. This suggests that sohlh2 may downregulate IL- 8 expression by binding directly to the IL- 8 promoter. We next performed reporter assay to investigate whether the IL- 8 promoter is inactivated by sohlh2. IL- 8 promoter activity was significantly repressed in sohlh2overexpressing MDA-MB-231 cells, while IL- 8 promoter activity was significantly stimulated in sohlh 2 knockdown MCF-7 cells (Figure 5E). It is known that IL-8 promoter is directly activated by $\mathrm{TNF} \alpha$ / NFאB signaling pathway. As shown in Figure 5F, sohlh2 partially blocked the activation of IL- 8 promoter caused by TNF $\alpha$. Chromatin immunoprecipitation assay identified the presence of the interacting IL-8 promoter fragments with sohlh2 in MDAMB-231 cells (Figure 5G).

\section{IL-8 compensates the negative effects of sohlh2 on EMT, migration, and invasion in breast cancer cells}

To test whether sohlh2-reduced metastatic capacity was mediated by downregulation of IL-8, human recombinant IL-8 was used in sohlh2-overexpressing MDA-MB-231 cells, and short hairpin RNAs (shRNAs) of IL-8 were used in sohlh2-ablated MCF7 cells. As expected, IL-8 significantly suppressed E-cadherin expression but increased vimentin expression at mRNA and protein levels in sohlh2-overexpressing MDA-MB-231 cells (Figure 6A-6C). Conversely, knockdown of IL-8 in sohlh2-ablated MCF7cells resulted in elevated E-cadherin expression and decreased vimentin expression at mRNA and protein levels (Figure 6A-6C). Moreover, IL-8 treatment significantly enhanced the reduced migratory and invasive capacities in sohlh2-overexpressing MDA-MB-231 cells, while IL-8 silencing significantly suppressed the elevated migratory and invasive capacities in sohlh2-ablated MCF7 cells (Figure 6D).
A

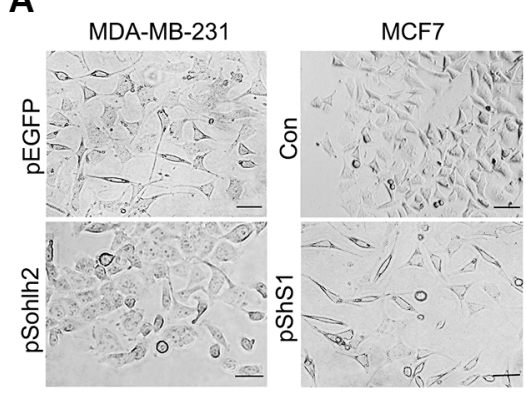

C

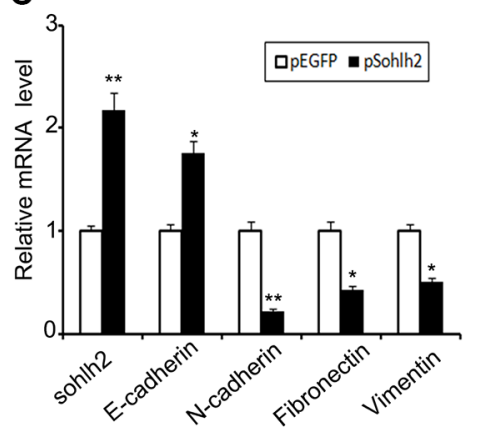

B
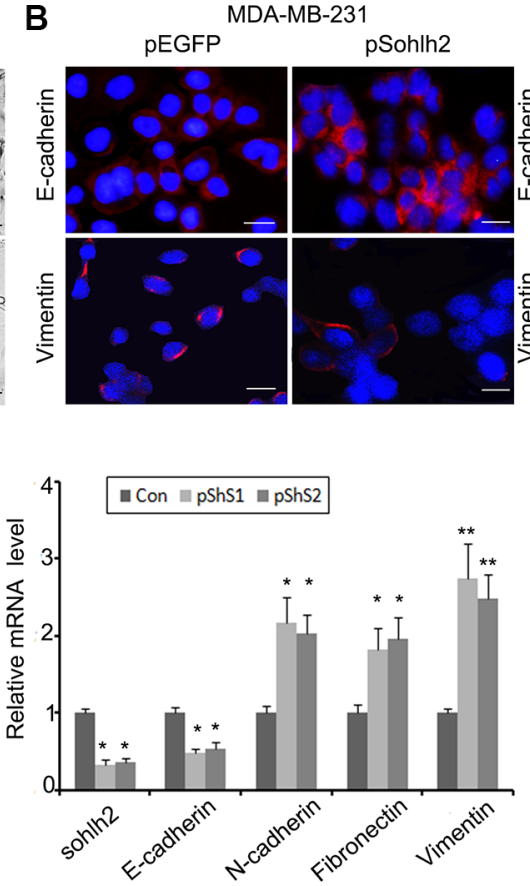
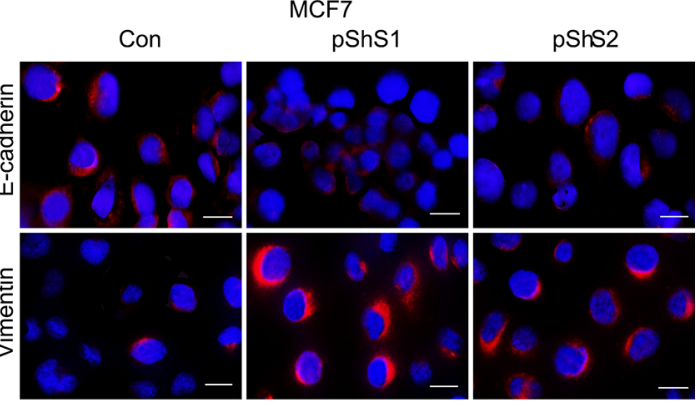

D

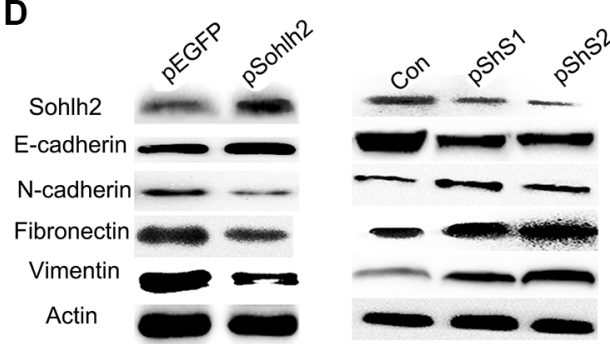

Figure 4: Sohlh2 suppresses EMT in breast cancer cells. (A) Phase contrast photographs show that pShS1-transfected MCF7 cells display fibroblastic morphology with increased cell spreading, while pSohlh2-transfected MDA-MB-231 cells display epithelial morphology. Scale bar $=100 \mu \mathrm{m}$. (B) Immunostaining of E-cadherin and vimentin in MDA-MB-231 and MCF-7 cells. The nuclei were stained by DAPI. Scale bar $=50 \mu \mathrm{m}$. (C) The mRNA expression of EMT markers including E-cadherin, N-cadherin, Fibronectin and vimentin in sohlh2-overexpressing MDA-MB-231 cells or sohlh2-ablated MCF-7 cells was examined by qPCR. (D) Cell lysates were prepared and the protein expression of EMT markers was analyzed by immunoblotting. $\beta$-actin was used as an internal control. All results are obtained from three independent experiments. $* P<0.05 ; * * P<0.01$. 


\section{Converse correlation of sohlh 2 and IL-8 expression in breast cancer tissues}

It has been reported that breast cancer patients who have abundant IL-8 protein expression are more likely to develop distant metastases and have a poor survival outcome [14-16]. To investigate the correlation between sohlh2 and IL-8 expression in breast cancer tissues, immunohistochemistry analysis was then performed on 77 paraffin-embedded breast cancer tissue samples. Two cases with typical sohlh2 and IL-8 staining are shown in Figure 7A. A significant correlation between sohlh2 and IL-8 expression ( $P=0.002$, Figure 7B) was found. IL-8 expression was negatively correlated with sohlh 2 expression in breast cancer tissues. These results suggest the presence of a sohlh2/IL-8 signaling in breast cancer samples.
A

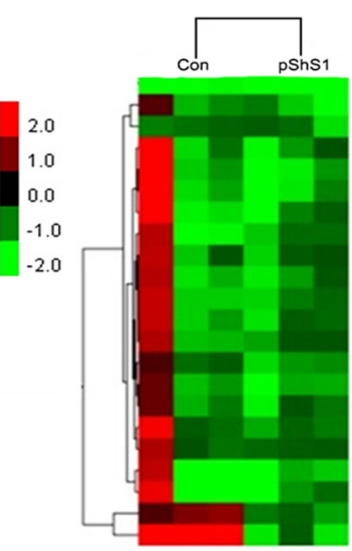

B
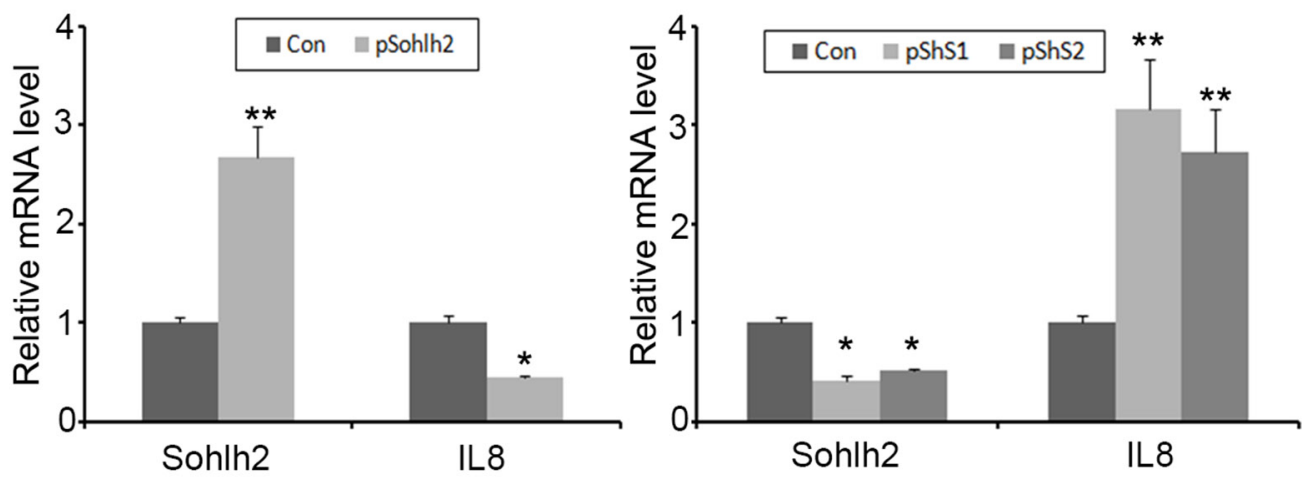

C

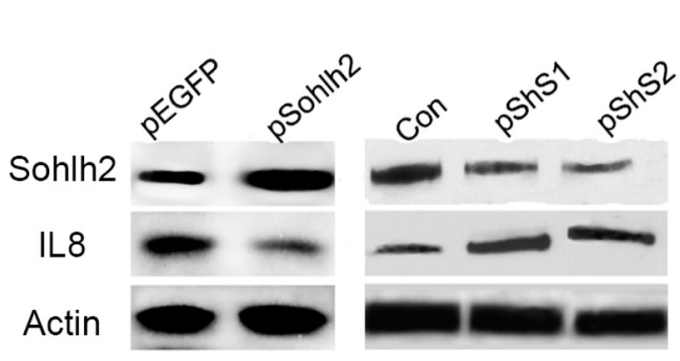

D

E

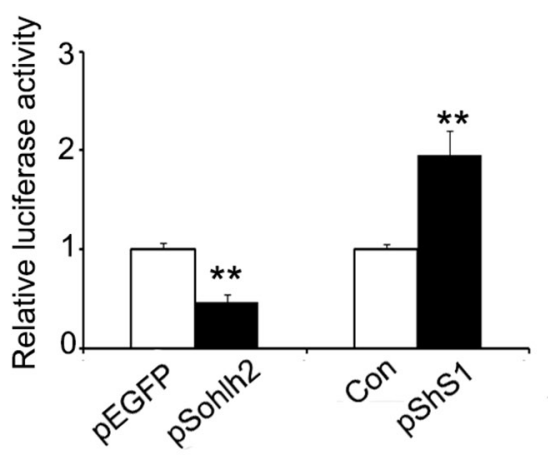

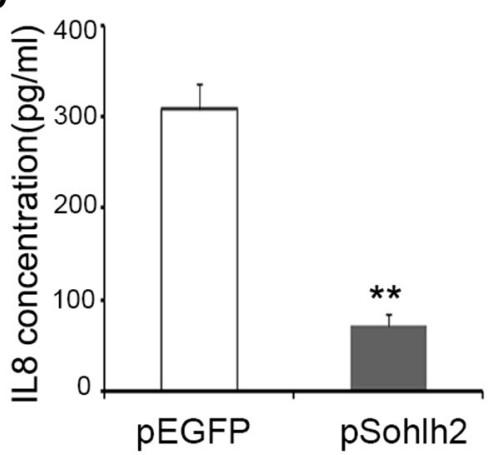

$\mathbf{F}$

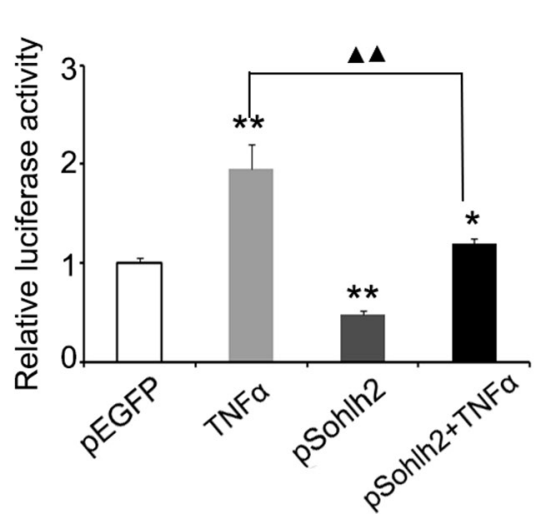

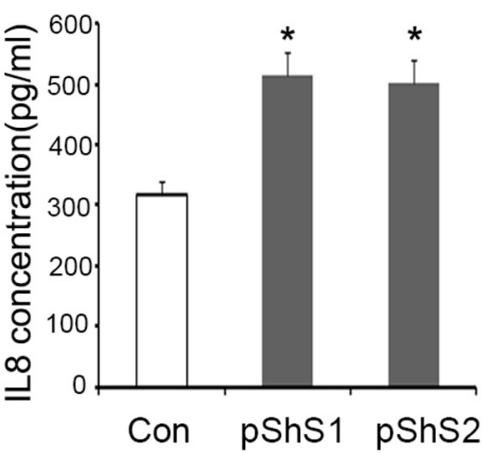

G

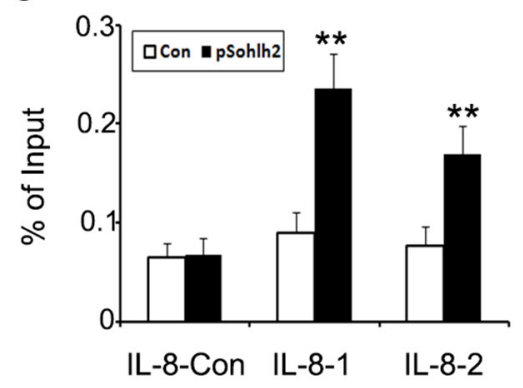

Figure 5: Sohlh2 regulates IL-8 expression. (A) Supervised hierarchical clustering of differentially expressed genes after sohlh2 knockdown in MCF-7 cells. (B, C) The mRNA (B) and protein (C) expression of IL-8 and sohlh2 in breast cancer cell lines. $\beta$-actin was used as a loading control. (D) Measurement of IL-8 secretion in sohlh2-overexpressing MDA-MB-231 and sohlh2-ablated MCF-7 cells by ELISA. E. Inhibition of pGL4-IL-8 luciferase activity by sohlh2 overexpression in MDA-MB-231 cells, and activation of pGL4-IL-8 luciferase activity by sohlh2 silencing in MCF-7 cells. (F) Sohlh2 partially repressed the activation of IL-8 promoter caused by TNFa. $\Delta \mathbf{\Delta} P<0.01$. (G) ChIP assay was carried out in sohlh2-overexpressing MDA-MB-231 cells. qPCR was performed to determine sohlh2 occupied abundance on IL-8 promoter with 2 primer pairs spanning E-Motifs and one control primer. qPCR results showed that sohlh2 bound to the specific regions of IL-8 promoter. Results represent mean \pm SD from three independent experiments. ${ }^{*} P<0.05 ;{ }^{* *} P<0.01$. 
A
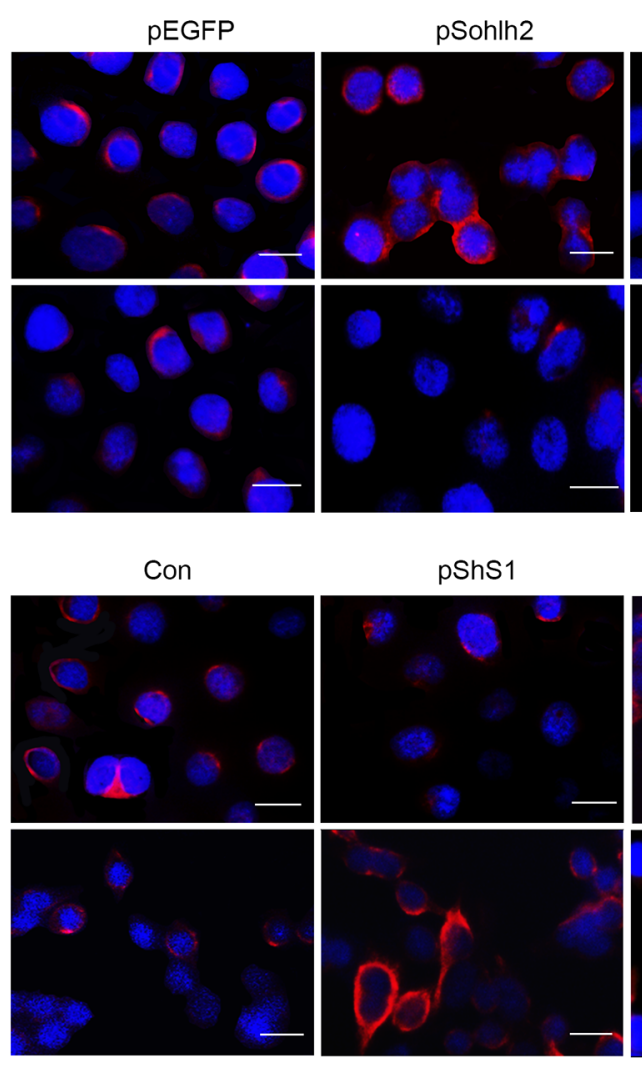

B

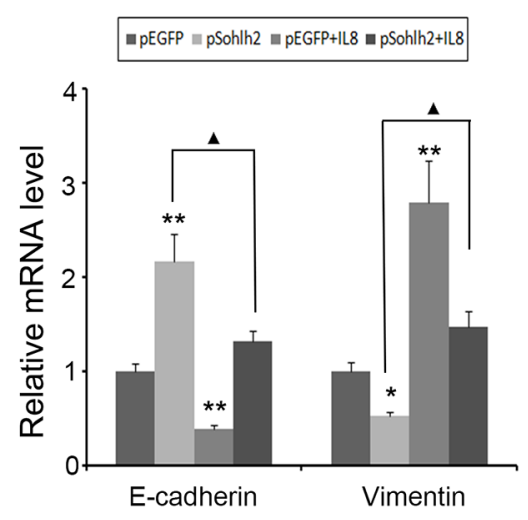

C

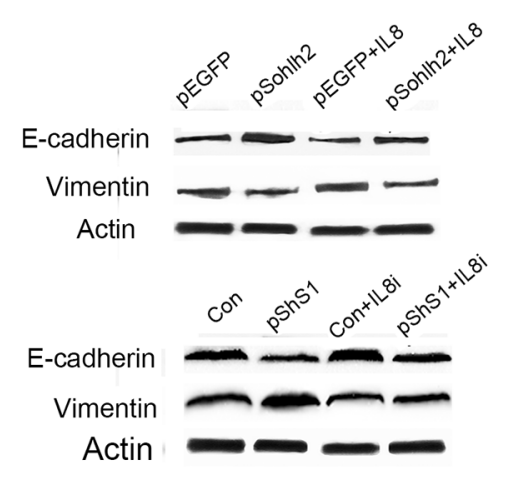

D
pEGFP+IL8

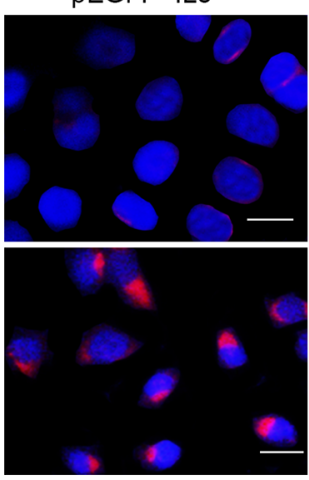

Con+IL8i
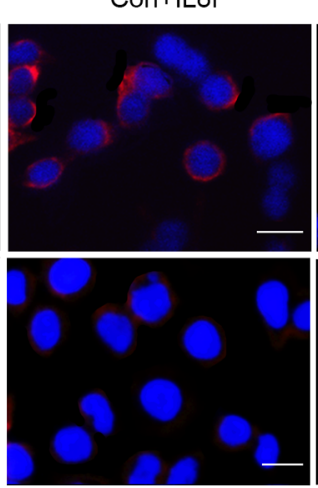

pSohlh2+IL8

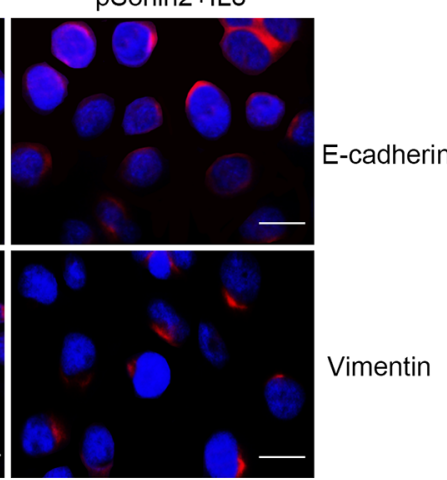

pShS1+IL8i

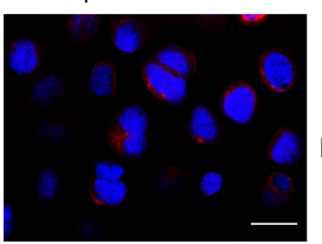

E-cadherin

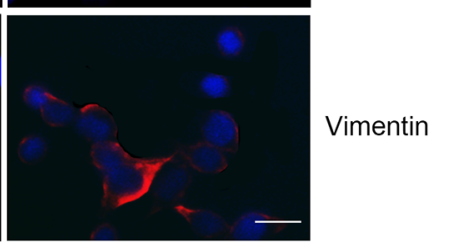

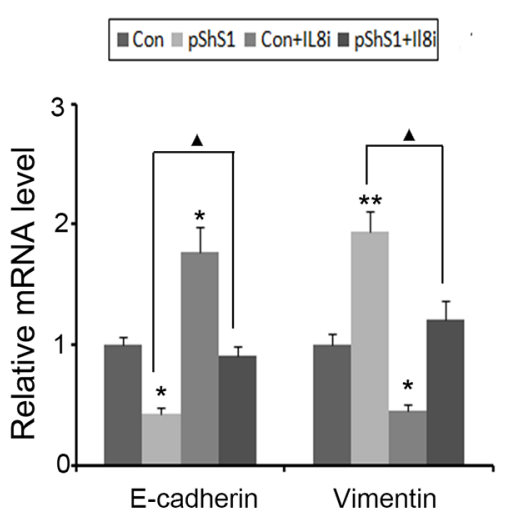
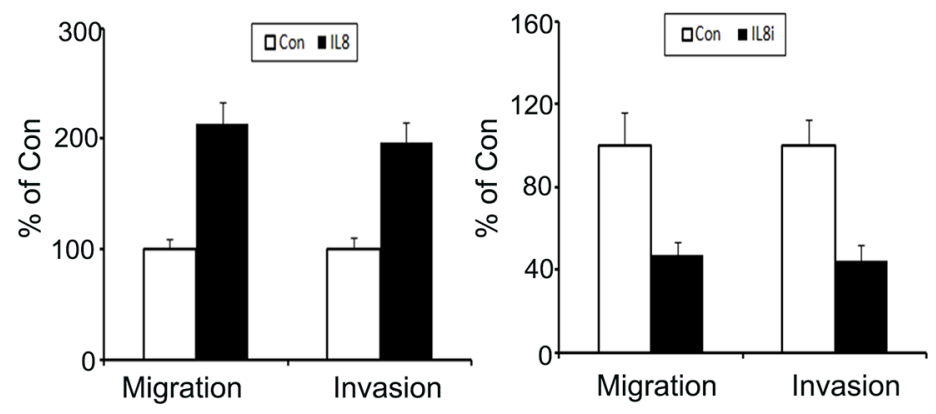

Figure 6: IL-8 is required for sohlh2-mediated EMT, migration and invasion. (A-C) IL-8 decreased E-cadherin expression but enhanced vimentin expression in sohlh2-overexpressing MDA-MB-231 cells. IL-8 Silencing induced the opposite effects in sohlh2ablated MCF-7 cells. (D) IL-8 enhanced transwell migration and Matrigel invasion in sohlh2-overexpressing MDA-MB-231 cells. IL-8 silencing inhibited transwell migration and Matrigel invasion in sohlh2-ablated MCF-7 cells. Scale bar $=50 \mu \mathrm{m}$. All results are obtained from three independent experiments. ${ }^{*} P<0.05 ; * * P<0.01$. 


\section{DISCUSSION}

In the current study, we observed that the expression of sohlh2, a bHLH transcription factor, was downregulated in breast cancer. The reduction in sohlh2 expression paralleled the invasion and metastasis of breast cancer. Invasive and migratory capabilities of breast cancer cell lines were significantly enhanced after sohlh2 knockdown, but significantly inhibited after sohlh2 overexpression. Sohlh2 overexpression also repressed the metastasis of breast cancer cells in vivo. A recent study by our group has shown that sohlh2 is repressed in ovarian carcinoma [11, 12]. Sohlh2 reduction shows strong associations with the metastasis and overall survival of ovarian cancer patients. Collectively, these results indicate sohlh2 is a novel tumor metastatic repressor.

EMT is associated with loss of epithelial features and gain of mesenchymal characteristics, resulting in increased invasive potential in epithelial cancer [5]. This study addressed the importance of sohlh2 in EMT and investigated the underlying molecular mechanisms.
We found that sohlh2 siRNA induced elongated and spindle-like morphology (mesenchymal phenotype) and significant alteration of EMT markers expression in MCF-7 cells. Conversely, sohlh2 overexpression in MDAMB-231 cells resulted in gain of epithelial characteristics and loss of mesenchymal characteristics, suggesting that sohlh2 is actively involved in the EMT process in breast cancer cells. Many bHLH transcription factors, such as Twist1, TCF4, DEC1, have been reported to act as strong promoters of EMT and metastatic spread in many human carcinomas [20-24]. However, a recent study revealed that a new bHLH transcription factor, E2A, is involved in suppressing the EMT process in colon cancer [25], which is consistent with our findings of repressed EMT by sohlh2. To the best of our knowledge, this is the first report suggesting the novel role of sohlh2 in the inhibition of EMT and metastasis in breast cancer cells.

Our study revealed a critical role of sohlh2/IL-8 signaling in EMT. In RNA-sequence results, IL- 8 is the most upregulated gene in sohlh2-ablated MCF7 cells. The inflammatory mediators, such as TNF $\alpha$, TGF $\beta$ and
A
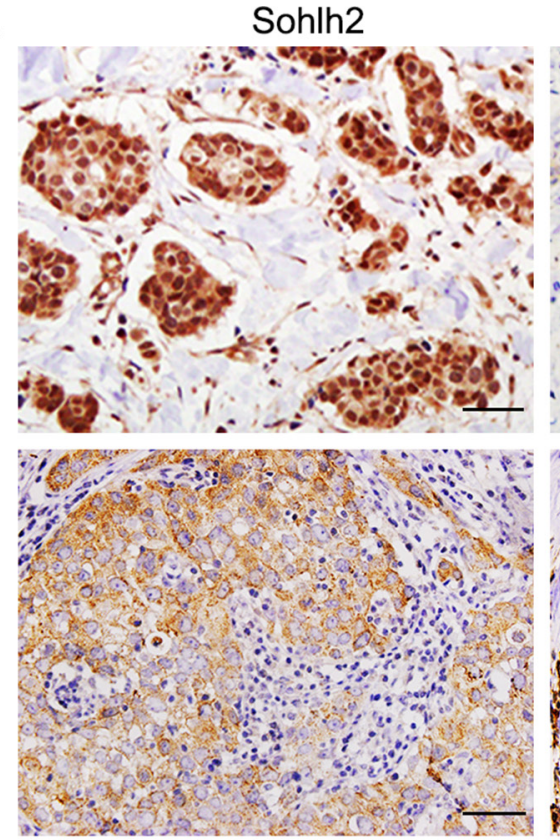

B

\begin{tabular}{lcc|c|c|}
\hline \multirow{2}{*}{$\begin{array}{c}\text { Sohlh2 } \\
\text { staining }\end{array}$} & \multirow{2}{*}{ Ho. of cases } & \multicolumn{3}{c}{ IL-8 staining } \\
\cline { 3 - 5 } & & $\begin{array}{c}\text { Positive } \\
(4-12)\end{array}$ & $\begin{array}{c}\text { Megative } \\
(0-3)\end{array}$ & $P$ \\
\hline Positive & 47 & $19(24.68 \%)$ & $28(36.36 \%)$ & \\
\hline Hegative & 30 & $23(29.87 \%)$ & $7(9.09 \%)$ & $p=0.002$ \\
\hline Total & 77 & $42(54.55 \%)$ & $35(45.45 \%)$ & \\
\hline
\end{tabular}

IL8

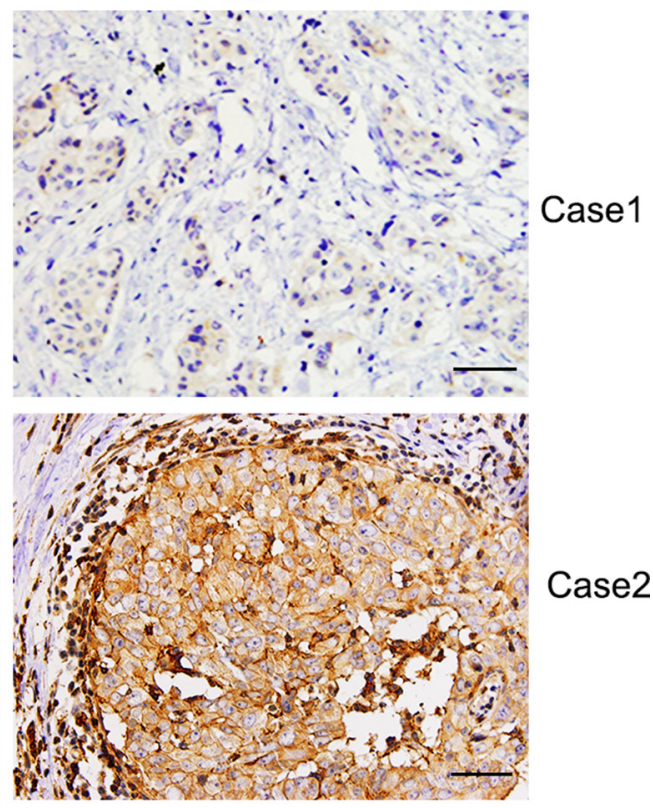

Case2

Figure 7: Correlation analysis of Sohlh2 expression with IL-8 in breast cancer specimens. (A) Immunohistochemical staining of Sohlh2 and IL-8 in adjacent sections from the same patient. Scale bar $=50 \mu \mathrm{m}$. (B) Chi-square analysis of the correlation between Sohlh2 levels and IL-8 levels in breast cancer specimens. 
IL-6, and snail have been implicated in the initiation of EMT [26-28]. IL-8 expression was elevated in both invasive cancer cells [29, 30] and the sera of patients with aggressive cancers $[31,32]$. Previous studies have reported that IL- 8 is involved in the regulation of EMT process $[18,19,33,34]$. Here we showed that sohlh2 inhibited IL-8 expression and EMT in breast cancer cells. Ectopic IL-8 addition in sohlh2-overexpressing MDAMB -231 cells blocked the inhibitory effect of sohlh2 on EMT. Moreover, the enhanced EMT induced by sohlh2 knockdown was abolished by IL- 8 silencing in breast cancer cells. This study indicates that IL-8 induction after sohlh2 knockdown is critical for EMT and thus provides a plausible molecular mechanism contributing to breast cancer aggressiveness.

Although IL-8 expression is regulated at both posttranscriptional and transcriptional levels, transcriptional regulation is of major importance for most stimuli, such as IL-1, TNFa, hypoxia, and acidic $\mathrm{pH}$ induces IL-8 expression in most types of cells [35-39]. In MDA-MB -231ER-negative breast cancer cells, IL-8 expression is positively regulated by $\mathrm{NF \kappa B}$, and synergistically cooperated by $\mathrm{AP}-1$ and $\mathrm{C} / \mathrm{EBP}$ transcription factors [40]. Indeed, we found that sohlh2 negatively regulated IL-8 expression at transcriptional level. Luciferase reporter and CHIP assays revealed that sohlh2 inhibited IL-8 expression in breast cancer cells via directly binding to IL-8 promoter. Moreover, sohlh2 partially attenuated the activation of IL-8 promoter stimulated by $\mathrm{TNF} \alpha$, suggesting the crosstalk between sohlh 2 and $\mathrm{TNF} \alpha / \mathrm{NF} \kappa \mathrm{B}$ signaling pathway on IL-8 transcription. Ten E-box motifs were identified in the human IL-8 promoter. bHLH transcription factor can bind to the E-box motifs on the IL-8 promoter and repress its activity [41]. In the future study, the specific E-box motifs bound by sohlh2 are worthy to be identified.

In conclusion, we provide the first evidence that sohlh2 inhibits EMT in breast cancer cells. The underlying mechanism involves direct disruption of IL-8 expression, which further leads to the inhibition of migration, invasion and metastasis of breast cancer cells. Overall, our results strongly support that sohlh2 regulates the motility, invasiveness and metastatic potentials of breast cancer cells by suppressing IL-8 expression.

\section{MATERIALS AND METHODS}

\section{Cell lines, plasmids and reagents}

The human breast cancer cell lines (MCF-7, MDAMB-231) and human transformed mammary epithelial cells (HBL-100, MCF-10a) used in this study were purchased from the Cell Bank of Type Culture Collection of the Chinese Academy of Sciences (Shanghai, China). The human breast cancer cells were cultured in DMEM medium supplemented with $10 \%$ fetal bovine serum (FBS;
Gibco, Life Technologies, Grand Island, NY) and 1\% penicillin-streptomycin. All cells were grown at $37^{\circ} \mathrm{C}$ in an atmosphere of $5 \% \mathrm{CO}_{2}$. All transfections were carried out using Lipofectamine 2000 (Invitrogen, Life Technologies).

The human sohlh2 cDNA was cloned into the pEGFP-N1 vector (Clontech, CA) to generate sohlh2overexpressing plasmid, pSohlh2. The luciferase reporter plasmid pGL4-IL-8 was constructed by cloning the 770 bp promoter regions of human IL-8 into the promoterless pGL4-basic vector (Promega, Madison, WI) as described previously [40]. The shRNAs were cloned into the GV428 vector (Genechem, Shanghai, China), using the mRNA targeted sequences as follows: Sohlh2: 5'- GC UCCAAUUCCUGACUAAUAC - 3' (pShS1) and 5'- UC UCCUGCCGUUAUGGCCCAGAUUA -3' (pShS2), IL-8: 5'- GCCAAGGAGUGCUAAAGAA -3' (pShIL-8). All constructs were verified by sequencing.

Antibodies to Sohlh2, fibronectin and IL-8 were purchased from Abcam Inc. (Cambridge, MA). E-cadherin, N-cadherin and vimentin antibodies were from Cell Signaling Technology (Beverly, MA). $\beta$-actin antibody was obtained from Santa Cruz Biotechnology Inc. (Santa Cruz, CA). Human recombinant IL-8 was purchased from Peprotech (Rocky Hill, NJ). TriZol was from Invitrogen. RT-PCR kit was from Thermo Fisher Scientific Inc. (Waltham, MA).

\section{Wound healing assay}

Cells were seeded in 6-well plates at a density of $5 \times 10^{5}$ cells/well. Confluent monolayers of cells were scratched with $10 \mu \mathrm{L}$ pipette tip to form a gap space of approximate $0.6 \mathrm{~mm}$. Cell debris was removed by PBS wash for three times. Photomicrographs were taken at 0 and $24 \mathrm{~h}$ after treatment. Five randomly selected points along each wound were marked, and the horizontal wound widths were measured using Image-Pro Plus 6.0 software. The migrated distance of cells was determined by subtracting the wound width at $24 \mathrm{~h}$ from its width at $0 \mathrm{~h}$. Experiments were carried out in triplicate and repeated at least three times.

\section{Migration assay}

Cell migration was determined by using a modified two chamber migration assay with a pore size of $8 \mathrm{~mm}$. For migration assay, $1 \times 10^{5} \mathrm{HBL}-100$ and MDA-MB-231 cells were seeded in serum-free medium in the upper chamber. After $12 \mathrm{~h}$ incubation at $37^{\circ} \mathrm{C}$, cells in the upper chamber were carefully removed with a cotton swab and the cells that had traversed the membrane were fixed in methanol and stained with leucocrystal violet. The number of migration cells was determined by counting the leucocrystal violet stained cells. For quantification, cells were counted under a microscope in five fields (up, down, median, left, right. $\times 200$ ). 


\section{Cell invasion assay}

Cells transfected with pSohlh2 or sohlh2 shRNAs (pShS1 and pShS2) were cultured at $\sim 80 \%$ confluence. Cells were starved in basal medium containing $0.2 \%$ bovine serum albumin for $16 \mathrm{~h}$. Matrigel cell invasion assay was carried out using the BD BioCoat Tumor Invasion System (BD Biosciences \#354165) as recommended by the manufacturer. $5 \times 10^{4}$ starved cells were seeded into the apical chambers, followed by adding a chemoattractant (basal medium plus 10\% FBS) to the basal chambers. After $24 \mathrm{~h}$ incubation, cells in the upper chamber were carefully removed with a cotton swab and the cells that had traversed the membrane were fixed in methanol and stained with leucocrystal violet. The number of invasive cells was determined by counting the leucocrystal violet stained cells. For quantification, cells were counted under a microscope in five fields (up, down, median, left, right. $\times 200$ ).

\section{Metastasis in vivo}

For experimental metastasis assay, $1 \times 10^{6}$ stable sohlh2-expressing MDA-MB-231cells (sohlh2 RNAi MCF-7 cells) or their parent cells were injected into 6-8 weeks old female BABL/c nude mice via tail vein. Eight weeks after injection, mice were euthanized, and lungs and livers were removed and subjected to histological examination.

For spontaneous metastasis assay, $5 \times 10^{6}$ Sohlh2 overexpressing MDA-MB-231cells were injected in the forth mammary fat pad of BABL/c nude mice. Lungs were either harvested from recipients at the same time as primary tumors (at a volume of approximately $1,000 \mathrm{~mm}^{3}$ ), 8 weeks after primary tumor resection $\left(500\right.$ to $\left.750 \mathrm{~mm}^{3}\right)$.

For each sample, all micro-metastases were counted under a light microscope at 10x magnification by an observer blinded to the experimental conditions. Six sections at $50 \mu \mathrm{m}$ interval were counted per mouse sample. Animal experiments were approved by the Laboratory Animal Ethics Committee of Shandong University and conformed to the legal mandates and national guidelines for the care and maintenance of laboratory animals.

\section{ELISA}

Breast cancer cell lines were transfected with control or pSohlh2 vector. Forty-eight hours after transfection, the vector- and sohlh2-expressing cells were seeded at a density of $1 \times 10^{5}$ cells per well in a 12-well plate and cultured for additional $24 \mathrm{~h}$. IL-8 concentration in culture supernatants was determined using ELISA kit (BD Biosciences) following manufacturer's instructions.

\section{Patient samples and immunohistochemistry}

77 cases of primary human invasive ductal breast cancer specimens, 16 cases of intraductal carcinoma in situ, and 25 cases of adjacent tissues to breast cancer were collected from patients at Qilu Hospital and Weifang People's Hospital from 2011 to 2013. The histological characterization and cell differentiation-based breast tumor grading were determined according to the current Union for International Cancer Control (UICC) criteria. The written consent was obtained from all patients and this study was approved by the Medical Ethics Committee of Shandong University.

The tissues were stained according to the standard immunostaining procedure [8]. Briefly, formalin-fixed and paraffin-embedded tissues were sectioned $(5 \mu \mathrm{m})$. After deparaffinization, sections were immunostained using anti-Sohlh2 and anti-IL-8 at 1:100 dilution. The slides were counterstained with hematoxylin and mounted. Control experiments were performed using non-immune immunoglobulins instead of the specific antibody. The immunostaining images were captured using the Olympus computerized image analysis system.

Each sample of Sohlh2 immunostaining was scored according to the intensity (no staining $=0$; weak staining $=1$; moderate staining $=2$; strong staining $=3$ ) and the percentage $(0 \%=0 ; 1-10 \%=1 ; 11-50 \%=2 ; 51-80 \%$ $=3 ; 81-100 \%=4)$ of stained cells. Final immunoreactive scores were determined by multiplying the intensity score with the percentage score, which ranged between 0 and $12[42,43]$. Sohlh2-positive expression was defined for tumors with Sohlh2-immunoreactive scores from 4 to 12, while Sohlh2-negative expression was defined for tumors with Sohlh2 immunoreactive scores from 0 to 3 .

\section{Quantitative real time-PCR}

Total RNA was prepared using TriZol reagent (Invitrogen) following the manufacturer's instructions. Five micrograms of total RNA was reverse-transcribed using the SuperScript II Reverse Transcriptase Kit (Invitrogen). A $25-\mu \mathrm{L}$ volume reaction consisted of $1 \mu \mathrm{L}$ reverse transcription product and $10 \mathrm{pM}$ of each primer. The specific primers used for RT-PCR were listed in Supplementary Table S2.

\section{Western blot}

Cells were lysed in RIPA lysis buffer (Santa Cruz). Total $25 \mu \mathrm{g}$ proteins were separated on a $10 \%$ SDSpolyacrylamide gel, and then transferred to polyvinylidene fluoride membranes (Millipore Corp, Billerica, MA). The membranes were probed with appropriate primary antibody at $4^{\circ} \mathrm{C}$ overnight, followed by incubation with peroxidase-conjugated anti-rabbit (or anti-goat) $\operatorname{IgG}$ antibody for $1 \mathrm{hr}$ at room temperature. The interaction was monitored with an enhanced chemiluminescence kit (Amersham Life Sciences Inc., GE Healthcare Life Sciences, Pittsburgh, PA). Anti- $\beta$-actin antibody was used to monitor the loading amount. 


\section{RNA sequencing}

The $3^{\prime}$ tag DGE libraries were constructed from sohlh2 RNAi MCF-7 cells as described in the Illumina DGE protocol. Total RNA (1-2 $\mu \mathrm{g})$ was fractionated using oligo-dT magnetic beads to yield poly(A+) mRNA. mRNA bound to the beads was then used as a template for first strand cDNA synthesis primed by oligo-dT and the second strand cDNA was consequently synthesized using random primers. The double strand cDNA is purified with magnetic beads and washed with EB buffer for end-polishing. Sequencing adapters are ligated to the fragments finally. The fragments are purified by magnetic beads and enriched by PCR amplification. The library products are ready for sequencing analysis via Illumina HiSeq $^{\mathrm{TM}}$ 2000. RNA sequencing yielded a mean read count of $\sim 12$ million reads per sample. After selection of intron-spanning (spliced) RNA reads and exclusion of genes with low coverage, we detected 15382 different protein coding and non-coding RNAs that were used for subsequent analyses. False discovery rate (FDR) $\leq 0.001$ and the absolute value of $\log _{2}$ Ratio, $\geq 1$ were used as the threshold to judge the significance of gene expression difference.

\section{ChIP assay}

ChIP analysis was performed as described previously [11]. Cells stably expressing sohlh 2 or control vector were prepared following the guidelines of ChIP assay kit (Upstate Chemicon). Chromatin solutions were precipitated with $30 \mu \mathrm{L}$ of agars containing anti-sohlh2 antibody (ab101402, Abcam) at $4^{\circ} \mathrm{C}$ overnight with agitation. For a negative control, rabbit $\operatorname{IgG}$ was used to incubate with the supernatant fraction for $1 \mathrm{~h}$ at $4{ }^{\circ} \mathrm{C}$ with rotation. Precipitated DNAs were analyzed by qPCR. The 3 primer pairs for human IL-8 promoters (two primer pairs spanning E-Motifs and one control primer) were as follows: IL-8-1: 5'- GATTGGCTGGCTTATCTTCACC -3' and 5'- TCCTTATCAAATACGGAGTATGACG -3 '(PCR product covering the sequences from -505 to -152 ); IL-8-2: 5'-GAAGCAACAGTGGCTGAACCAG -3'and 5'-GAAG TGAGACAATTGTACGTAA -3'( from -1110 to -640 ); IL-8-con: 5'-TGTGAGCATCAAGGTTAAGTAG -3'and 5'-CTTAGTCAGTTCGGTCCAACACAG $\quad-3$ '(from -2443 to -2183 )

\section{Luciferase reporter assay}

$5 \times 10^{4}$ MDA-MB-231 cells were plated in 24-well plate and transiently transfected with $200 \mathrm{ng}$ of sohlh2 plasmid, $100 \mathrm{ng}$ of IL-8 promoter firefly luciferase reporter construct and $17 \mathrm{ng}$ of Renilla luciferase plasmid (Promega) using Lipofectamine 2000 (Invitrogen). Luciferase activities were determined 24 hours after transfection using a dual-luciferase reporter assay system
(Promega). Results were represented as the ratio of firefly to Renilla luciferase activity and normalized to vector control.

\section{Statistical analysis}

Quantitative data are expressed as mean \pm standard deviation (SD). GraphPad Prism (GraphPad Software, San Diego, CA) was used for data analysis. The Student $t$ test or one-way analysis of variance (ANOVA) was used to assess significant differences between groups. The Chi-square test was used to analyze the relationship between categorical variables. $P<0.05$ was considered statistically significant.

\section{ACKNOWLEDGMENTS AND FUNDING}

This research was supported by the National Natural Science Foundation of China (Grant No. 31071269), the Shandong Department of Science and Technology Plan Project (Grant No.2014GSF118085) and the Natural Science Foundation of Shandong Province (Grant No. ZR 2014HM082).

\section{CONFLICTS OF INTEREST}

The authors declare no conflicts of interest.

\section{REFERENCES}

1. Jemal A, Bray F, Center MM, Ferlay J, Ward E, Forman D. Global cancer statistics. CA Cancer J Clin. 2011; 61:69-90.

2. Lorusso G, Ruegg C. New insights into the mechanisms of organ-specific breast cancer metastasis. Semin Cancer Biol. 2012; 22:226-33.

3. Valastyan S, Weinberg RA. Tumor metastasis: molecular insights and evolving paradigms. Cell. 2011; 147:275-92.

4. Foroni C, Broggini M, Generali D, Damia G. Epithelialmesenchymal transition and breast cancer: role, molecular mechanisms and clinical impact. Cancer Treat Rev. 2012; 38:689-97.

5. Gao D, Vahdat LT, Wong S, Chang JC, Mittal V. Microenvironmental regulation of epithelial-mesenchymal transitions in cancer. Cancer Res. 2012; 72:4883-9.

6. Puisieux A, Brabletz T, Caramel J. Oncogenic roles of EMT-inducing transcription factors. Nat Cell Biol. 2014; 16:488-94.

7. Tania M, Khan MA, Fu J. Epithelial to mesenchymal transition inducing transcription factors and metastatic cancer. Tumour Biol. 2014; 35:7335-42.

8. Ballow DJ, Xin Y, Choi Y, Pangas SA, Rajkovic A. Sohlh2 is a germ cell-specific bHLH transcription factor. Gene Expr Pattern. 2006; 6:1014-1018.

9. Hao J, Yamamoto M, Richardson TE, Chapman KM, Denard BS, Hammer RE, Zhao, GQ, Hamra FK. Sohlh2 knockout mice are male-sterile because of degeneration of 
differentiating type A spermatogonia. Stem Cells. 2008; 26:1587-1597.

10. Sun H, Ghaffari S, Taneja R. bHLH-Orange Transcription Factors in Development and Cancer. Transl Oncogenomics. 2007; 2:107-20.

11. Zhang H, Zhang X, Ji S, Zhang X, Zhang W, Zhao Q, Sun J, Hao J. Sohlh2 inhibits ovarian cancer cell proliferation by upregulation of p21 and downregulation of cyclin D1. Carcinogenesis. 2014; 35;1863-71.

12. Zhang H, Hao C, Wang Y, Ji S, Zhang X, Zhang W, Zhao Q, Sun J, Hao J. Sohlh2 inhibits human ovarian cancer cell invasion and metastasis by transcriptional inactivation of MMP9. Mol Carcinog. 2016; 55:1127-37.

13. Ali S, Lazennec G. Chemokines: novel targets for breast cancer metastasis. Cancer Metastasis Rev. 2007; 26:401-20.

14. Waugh DJ, Wilson C. The interleukin-8 pathway in cancer. Clin Cancer Res. 2008; 14:6735-6741

15. Freund A, Chauveau C, Brouillet JP, Lucas A, Lacroix M, Vignon F, Lazennec Gl. IL-8 expression and its possible relationship with estrogen-receptor-negative status of breast cancer cells. Oncogene. 2003; 22:256-65.

16. Yao C, Lin Y, Chua MS, Ye CS, Bi J, Zhu YF, Wang SM. Interleukin-8 modulates growth and invasiveness of estrogen receptor-negative breast cancer cells. Int J Cancer 2007; 121:1949-57.

17. Benoy IH, Salgado R, Van Dam P, Geboers K, Van Marck E, Vermeulen PB, Dirix LY. Increased serum interleukin-8 in patients with early and metastatic breast cancer correlates with early dissemination and survival. Clin Cancer Res. 2004; 10:7157-62.

18. Fernando RI, Castillo MD, Litzinger M, Hamilton DH, Palena C. IL-8 signaling plays a critical role in the epithelialmesenchymal transition of human carcinoma cells. Cancer Res. 2011; 71:5296-306.

19. Fu XT, Dai Z, Song K, Zhang ZJ, Zhou ZJ, Zhou SL, Zhao YM, Xiao YS, Sun QM, Ding ZB, Fan J. Macrophagesecreted IL-8 induces epithelial-mesenchymal transition in hepatocellular carcinoma cells by activating the JAK2/ STAT3/Snail pathway. Int J Oncol. 2015; 46:587-96.

20. Nuti SV, Mor G, Li P, Yin G. TWIST and ovarian cancer stem cells: implications for chemoresistance and metastasis. Oncotarget. 2014; 5:7260-71. doi: 10.18632/ oncotarget.2428.

21. Mitra A, Mishra L, Li S. EMT, CTCs and CSCs in tumor relapse and drug-resistance. Oncotarget. 2015; 6:10697-711. doi: 10.18632/oncotarget.4037.

22. Lamouille S, Xu J, Derynck R. Molecular mechanisms of epithelial-mesenchymal transition. Nat Rev Mol Cell Biol. 2014; 15:178-196.

23. Wu Y, Sato F, Yamada T, Bhawal UK, Kawamoto T, Fujimoto K, Noshiro M, Seino $H$, Morohashi S, Hakamada K, Abiko Y, Kato Y, Kijima H. The BHLH transcription factor DEC1 plays an important role in the epithelial-mesenchymal transition of pancreatic cancer. Int J Oncol. 2012; 41:1337-46.
24. Cano A, Portillo F. An emerging role for class I bHLH E2-2 proteins in EMT regulation and tumor progression. Cell Adh Migr. 2010; 4:56-60.

25. Zhao H, Huang A, Li P, Quan Y, Feng B, Chen X, Mao Z, Zhu Z, Zheng M. E2A suppresses invasion and migration by targeting YAP in colorectal cancer cells. J Transl Med. 2013; 11:317-325.

26. Liu J, Hu G, Chen D, Gong AY, Soori GS, Dobleman TJ, Chen XM. Suppression of SCARA5 by Snaill is essential for EMT-associated cell migration of A549 cells. Oncogenesis. 2013; 2:73-82.

27. Sullivan NJ, Sasser AK, Axel AE, Vesuna F, Raman V, Ramirez N, Oberyszyn TM, Hall BM. Interleukin-6 induces an epithelial-mesenchymal transition phenotype in human breast cancer cells. Oncogene. 2009; 28:2940-2947.

28. Wu Y, Deng J, Rychahou PG, Qiu S, Evers BM, Zhou BP. Stabilization of snail by NF-kappaB is required for inflammation-induced cell migration and invasion. Cancer Cell. 2009; 15:416-428.

29. De Larco JE, Wuertz BR, Rosner KA, Erickson SA, Gamache DE, Manivel JC, Furcht LT. A potential role for interleukin- 8 in the metastatic phenotypeof breast carcinoma cells. Am J Pathol. 2001; 158:639-646.

30. Green AR, Green VL, White MC, Speirs V. Expression of cytokine messenger RNA in normal and neoplastic human breast tissue: identification of interleukin- 8 as a potential regulatory factor in breast tumours. Int J Cancer. 1997; 72:937-941.

31. Benoy IH, Salgado R, Van Dam P, Geboers K, Van Marck E, Scharpé S, Vermeulen PB, Dirix LY. Increased Serum Interleukin-8 in Patients with Early and Metastatic Breast Cancer Correlates with Early Dissemination and Survival. Clinical Cancer Research. 2004; 10:7157-7162.

32. Orditura M, De Vita F, Catalano G, Infusino S, Lieto E, Martinelli E, Morgillo F, Castellano P, Pignatelli C, Galizia G. Elevated serum levels of interleukin-8 in advanced nonsmall cell lung cancer patients: relationship with prognosis. J Interferon Cytokine Res. 2002; 22:1129-1135.

33. Yin J, Zeng $\mathrm{F}$, Wu N, Kang $\mathrm{K}$, Yang Z, Yang $\mathrm{H}$. Interleukin-8 promotes human ovarian cancer cell migration by epithelial-mesenchymal transition induction in vitro. Clin Transl Oncol. 2015; 17:365-70

34. Yu J, Ren X, Chen Y, Liu P, Wei X, Li H, Ying G, Chen K, Winkler H, Hao X. Dysfunctional activation of neurotensin/IL-8 pathway in hepatocellular carcinoma is associated with increased inflammatory response in microenvironment, more epithelial mesenchymal transition in cancer and worse prognosis in patients. PLoS One. 2013; 8:e56069-83.

35. Xu L, Xie K, Mukaida N, Matsushima K, Fidler IJ. Hypoxia induced elevation in interleukin- 8 expression by human ovarian carcinoma cells. Cancer Res. 1999; 59:5822-9.

36. Mukaida N, Mahe Y, Matsushima K. Cooperative interaction of nuclear factor-kappa B- and cis-regulatory 
enhancer binding proteinlike factor binding elements in activating the interleukin- 8 gene by pro-inflammatory cytokines. J Biol Chem. 1990; 265:21128-33.

37. Kasahara $T$, Mukaida N, Yamashita $K$, Yagisawa $H$, Akahoshi T, Matsushima K. IL-1 and TNF-alpha induction of IL-8 and monocyte chemotactic and activating factor (MCAF)mRNA expression in a human astrocytoma cell line. Immunology. 1991; 74:60-7.

38. Xu L, Fidler IJ. Acidic pH-induced elevation in interleukin 8 expression by human ovarian carcinoma cells. Cancer Res. 2000; 60:4610-6.

39. Roebuck KA. Regulation of interleukin-8 gene expression. J Interferon Cytokine Res. 1999; 19:429-38.

40. Freund A, Jolivel V, Durand S, Kersual N, Chalbos D, Chavey C, Vignon F, Lazennec G. Mechanisms underlying differential expression of interleukin- 8 in breast cancer cells. Oncogene. 2004; 23:6105-14.
41. Li XH, Kishore AH, Dao D, Zheng W, Roman CA, Word RA. A novel isoform of microphthalmia-associated transcription factor inhibits IL-8 gene expression in human cervical stromal cells. Mol Endocrinol. 2010; 24:1512-28.

42. Han CP, Kok LF, Wang PH, Wu TS, Tyan YS, Cheng YW, Lee MY, Yang SF. Scoring of p16(INK4a) immunohistochemistry based on independent nuclear staining alone can sufficiently distinguish between endocervical and endometrial adenocarcinomas in a tissue microarray study. Mod Pathol. 2009; 22:797-806.

43. Kamo M, AlJuboury MI, Akin MR, Silverberg SG. Immunohistochemical staining in the distinction between primary endometrial and endocervical adenocarcinomas: another viewpoint. Int J Gynecol Patho. 2001; 21:217-23. 